\title{
Penerapan Enhanced Recovery after Surgery (ERAS) pada Bedah Saraf
}

\author{
Riyadh Firdaus*), Affan Priyambodo Permana**), Astrid Indrafebrina Sugianto*), Sandy Theresia*) \\ ${ }^{*}$ Departemen Anestesiologi dan Terapi Intensif, Fakultas Kedokteran Universitas Indonesia, Rumah Sakit Cipto \\ Mangunkusumo, ${ }^{* *}$ Departemen Bedah Saraf, Fakultas Kedokteran Universitas Indonesia, Rumah Sakit Cipto \\ Mangunkusumo
}

\begin{abstract}
Abstrak
Enhanced recovery after surgery atau ERAS adalah suatu protokol perawatan perioperasi terstandar multidisiplin pada pasien bedah yang bertujuan untuk meminimalkan stres perioperasi sehingga menghasilkan luaran yang lebih baik. Protokol ERAS tersusun dari berbagai komponen perawatan yang terbukti mendukung pemulihan dan/atau menghindari komplikasi pascaoperasi. Komponen-komponen tersebut mengikutsertakan ahli bedah, ahli anestesi, perawat, farmasi, ahli gizi yang terlibat dalam perawatan pasien sehingga memberikan perbaikan yang lebih baik. Protokol ERAS tersusun dari berbagai komponen perawatan dari mulai praoperasi (konseling, pemberian nutrisi, pengelolaan kebiasaan, trombofilaksis, persiapan daerah operasi dan profilaksis antimikroba), intraoperasi (teknik anestesi, manajemen anestesi, analgesia, manajemen cairan, pengaturan suhu, teknik pembedahan) hingga pascaoperasi (kejadian post-operative nausea and vomiting (PONV), drainase urin, asupan nutrisi, mobilisasi dini). Penerapan ERAS menunjukkan hasil yang baik, dapat diterapkan, dan memberikan keuntungan bagi pasien bedah saraf. Walau demikian, protokol ERAS dalam bedah saraf masih sangat terbatas dan memerlukan penelitian lebih lanjut mengikuti berbagai jenis tindakan/operasi dan keadaan pasien yang berbeda-beda.
\end{abstract}

kata kunci: ERAS, Bedah Saraf

JNI 2021; 10 (2): 144-150

\section{Implementation of Enhanced Recovery after Surgery (ERAS) in Neurosurgery}

\begin{abstract}
Enhanced recovery after surgery (ERAS) is a multidisciplinary standardized perioperative treatment protocol in surgical patients that aims to minimize perioperative stress and result in better outcomes. The ERAS protocol is composed of various components of care that have been shown to support recovery and/or avoid postoperative complications. These components include surgeons, anesthesiologists, nurses, pharmacists, nutritionists who are involved in patient care to provide better improvements. The ERAS protocol is composed of various components of preoperative care (counseling, nutrition, lifestyle management, thromboprophylaxis, preparation of the surgical area and antimicrobial prophylaxis), intraoperative care (anesthetic technique, anesthesia management, analgesia, fluid management, temperature regulation, surgical technique) and postoperative care (PONV management, urinary drainage, nutritional intake, early mobilization). Implementation of ERAS is applicable and shows good results along with the benefits for patients undergoing neurosurgery. However, ERAS in neurosurgery is still very limited and requires further research following different types of procedures / operations and different patient conditions.
\end{abstract}

Key words: ERAS, Neurosurgery

JNI 2021; 10 (2): 144-150

This article is licensed under a

Creative Commons Attribution-NonCommercial-ShareAlike 4.0 International License.

CRiyadh Firdhaus, Affan Priyambodo Permana, Astrid Indrafebrina Sugianto, Sandy

Theresia. (2021) under the CC-BY-NC-SA license 


\section{Pendahuluan}

Enhanced recovery after surgery (ERAS) adalah suatu protokol perawatan perioperasi terstandar yang melibatkan berbagai disiplin medis pada pasien bedah. Pendekatan multimodal ini bertujuan meminimalkan stres perioperasi sehingga menghasilkan keluaran yang lebih baik. Henry Kenlet memperkenalkan ERAS pada tahun 1997 yang didesain untuk operasi reseksi kolon. Studi tersebut kemudian menjadi cikal bakal perkembangan ERAS di bidang pembedahan secara lebih luas...-2 Saat ini, ERAS telah diterapkan dalam beberapa intervensi bedah, seperti operasi ortopedi, bedah digestif, dan bariatrik. ERAS terbukti efektif pada berbagai pembedahan tersebut. $-\frac{3-6}{-6}$ Protokol ERAS tersusun dari berbagai komponen perawatan (Gambar 1) yang telah terbukti mendukung pemulihan dan/atau menghindari komplikasi pascaoperasi. Komponen-komponen tersebut mengikutsertakan semua pihak (ahli bedah, ahli anestesi, perawat, farmasi, ahli gizi) yang terlibat dalam perawatan pasien sehingga memberikan perbaikan pada pasien yang lebih baik, terutama dalam pengurangan durasi rawat inap di rumah sakit antara $\underline{1}, \underline{5}-\underline{5}, \underline{5}$ hari, angka re-admisi rumah sakit dan tingkat komplikasi pasca operasi hingga 50\% (angka ini bervariasi tergantung pada jenis tindakan/operasi dan karakteristik pasien), dan angka kematian pasca operasi. Secara keseluruhan, ERAS mempercepat proses pemulihan sebesar $30-50 \% .1,-2,7,8$

\section{ERAS pada Perawatan Praoperasi}

\section{Konseling}

Konseling menjadi bagian penting dari ERAS karena memiliki dampak yang signifikan terhadap kepuasan serta persepsi pasien terkait tindakan bedah yang akan dilakukan. Pemberian informasi secara komprehensif kepada pasien menjadi faktor penting dalam konseling, diantaranya berupa informasi terkait durasi rawat inap, rencana tatalaksana, hasil yang diharapkan, kemungkinan buruk yang mungkin terjadi pasca operasi, dan perawatan pascaoperasi yang harus dijalankan oleh pasien. Selain itu, beberapa studi menunjukkan bahwa konseling menurunkan tingkat ansietas pasien secara signifikan. ${ }^{9,10}$

\section{Nutrisi}

Status gizi praoperasi yang buruk dikaitkan dengan peningkatan morbiditas dan lama perawatan (length of stay/ LOS) di rumah sakit. Oleh karena itu, pemberian dukungan nutrisi, baik nutrisi makro maupun mikro, untuk memperbaiki status gizi pasien penting untuk dilakukan. Makan enam jam sebelum operasi dan asupan cairan jernih/ clear liquid (termasuk cairan glukosa per oral) hingga dua jam sebelum tindakan bedah dapat diterapkan, baik pada pada pasien yang akan menjalani pembedahan. Hal ini terbukti menurunkan resistensi insulin pasca pembedahan, timbulnya rasa lelah, dan perasaan lapar serta haus pascaoperasi jika dibandingkan dengan pasien yang berpuasa. ${ }^{9} 10$

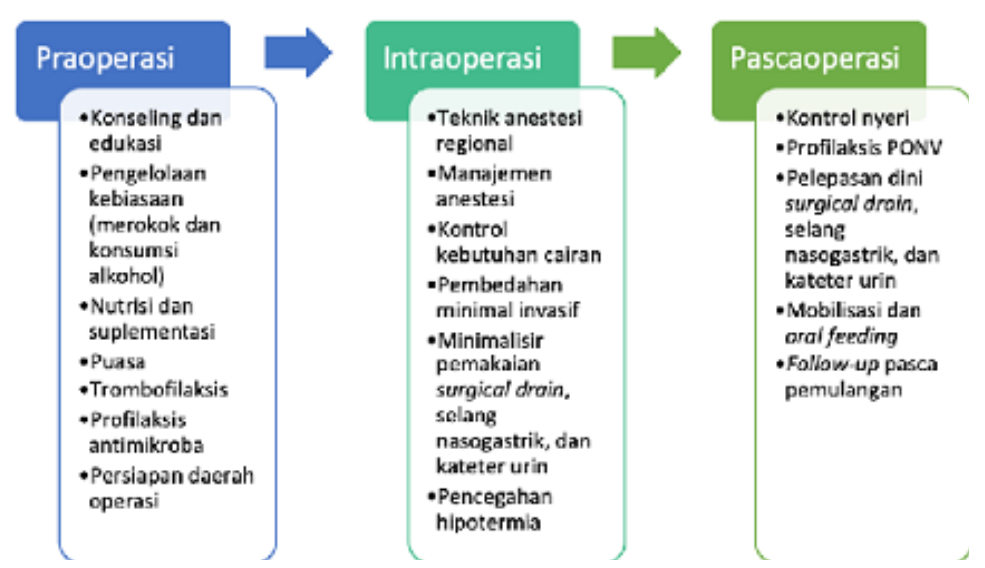

Gambar 1. Komponen pada Protokol ERAS 
Resistensi insulin pasca pembedahan pada sistem saraf pusat mengakibatkan efek neuroprotektif insulin menurun, meningkatkan nekrosis dan/ atau apoptosis neuron, dan memperlambat proses pemulihan pasien. ${ }^{11-13}$ Puasa praoperasi yang terlalu panjang juga memberikan dampak negatif pada metabolisme tubuh ${ }^{9}$

\section{Pengelolaan Kebiasaan Merokok dan Minum Alkohol}

Konsumsi alkohol dan merokok meningkatkan risiko morbiditas dan mortalitas pascaoperasi. Pantang konsumsi alkohol selama satu bulan sebelum operasi menunjukkan penurunan morbiditas pascaoperasi, sedangkan pantang merokok selama satu bulan menurunkan risiko komplikasi paru dan komplikasi pemulihan.

Pada kelompok perokok, baik perokok ringan hingga berat, terdapat peningkatan konsentrasi residu, seperti nikotin, di pembuluh darah otak. Residu ini mampu memicu penumpukan metabolit transien dengan efek vasodilatasi di pembuluh darah, menyebabkan cedera jaringan endotel, sehingga akhirnya mengakibatkan terjadinya hiperemia akut. Hiperemia dan vasodilatasi akut ini selanjutnya dapat meningkatkan aliran darah di dalam pembuluh darah otak dan menyebabkan peningkatan perdarahan intraoperasi kraniotomi. Pantang konsumsi alkohol dan merokok satu bulan sebelum operasi dapat dilakukan jika memungkinkan, disesuaikan dengan kasus serta kondisi setiap pasien. ${ }^{10,14,15}$

\section{Trombofilaksis}

Trombofilaksis pada tindakan kraniotomi dilakukan dengan metode mekanis, meliputi kompresi dengan stocking dan perangkat kompresi pneumatik intermiten. Trombofilaksis mekanis berfungsi untuk menghindari tromboemboli vena. Trombofilaksis dengan obat-obatan dihindari karena dapat menimbulkan komplikasi yang signifikan seperti perdarahan intrakranial. ${ }^{16}$

\section{Persiapan Daerah Operasi dan Profilaksis Antimikroba}

Studi tentang mencukur rambut kepala menunjukkan tidak ada perbedaan tingkat infeksi daerah operasi antara pasien yang dicukur sebelum operasi dan yang tidak dicukur. Staphylococcus aureus bertanggung jawab atas $32 \%$ infeksi daerah operasi pasca kraniotomi. Mayoritas pedoman saat ini tetap merekomendasikan cefazolin sebagai pilihan lini pertama untuk profilaksis antibiotik pada kraniotomi. Pengecualian untuk rekomendasi ini adalah pasien dengan $\mathrm{S}$. aureus resisten methicillin (MRSA), sebaiknya diberikan vankomisin yang dimulai 1 jam sebelum insisi kulit. ${ }^{10}$

\section{ERAS pada Perawatan Intraoperasi}

\section{Teknik Anestesi}

Anestesi kulit kepala pada tindakan kraniotomi dapat dilakukan dengan teknik infiltrasi (umumnya mengikuti garis insisi) dan blok. Teknik anestesi infiltrasi dan blok menghasilkan kontrol hemodinamik dan respons stres yang lebih baik serta mengurangi kebutuhan pemberian opioid. Penggunaan anestesi regional juga dapat dilakukan pada bedah spinal dengan tujuan untuk menghindari komplikasi intubasi orotrakea dan gangguan homeostasis, serta pemantauan neurologis secara langsung. Namun hal ini menyebabkan keterbatasan waktu operasi dan jalan napas pasien tidak aman, sehingga direkomendasikan untuk dilakukan monitoring intraoperasi yang lebih tat. ${ }^{6}{ }^{12}$

\section{Manajemen Anestesi}

Anestesi intravena total (Total Intravenous Anesthesia/TIVA) tidak memiliki perbedaan secara signifikan dibandingkan dengan anestesi inhalasi pada tindakan kraniotomi. Penggunaan opioid kerja lama dibandingkan kerja pendek juga didak ditemukan perbedan yang signifikan. 6 Penggunaan lidokain intravena dan ketamin kurang cocok untuk pasien dengan tindakan kraniotomi karena memiliki efek samping yang berdampak signifikan pada pasien. Ketamin dapat menimbulkan halusinasi, mual, muntah, pusing, dan pandangan kabur. Lidokain intravena dapat memberikan hasil pascaoperasi yang lebih baik, namun profil sedasinya dapat mengganggu penilaian kognitif pasien pascaoperasi. Penggunaan dinitrogen oksida $\left(\mathrm{N}_{2} \mathrm{O}\right)$ juga perlu dipertimbangkan lebih lanjut untuk pasien kraniotomi karena meningkatkan 
laju metabolisme otak, aliran darah otak (cerebral blood flow/CBF), tekanan intra kranial (intracranial pressure/ICP), dan mual dan muntah pascaoperasi (post-operative nausea and vomiting/PONV). $\underline{6}$

\section{Manajemen Cairan}

Kontrol asupan cairan perioperasi penting untuk dilakukan pada bedah saraf. Cairan perioperasi umumnya dibatasi untuk menciptakan kondisi operasi yang optimal pada tindakan kraniotomi. Namun demikian, keadaan ini juga dapat menyebabkan defisit cairan relatif sehingga pemantauan hemodinamik yang lebih ketat perlu dilakukan. Sementara itu, bedah spinal lebih umum menggunakan neutral net fluid effect, yaitu keadaan balans cairan mendekati nol. Manajemen cairan masih memerlukan penelitian lebih lanjut untuk mengevaluasi peran terapi cairan dalam ERAS untuk prosedur bedah saraf., ${ }^{9,10}$

\section{Suhu}

Terapi hipotermia dan normotermia merupakan dua pilihan tindakan yang umum dilakukan pada pasien bedah saraf. Studi menunjukkan bahwa tidak terdapat hasil yang signifikan pada penurunan angka kematian dan perbedaan keluaran klinis yang kurang menguntungkan pada pasien bedah saraf yang mendapatkan perlakukan therapeutic hypothermia dibandingkan dengan normotermia. ${ }^{18}$ Mempertahankan pasien dalam kondisi normotermia diketahui dapat menurunkan angka cardiac event, perdarahan, kebutuhan transfusi, infeksi, dan ulkus dekubitus pada pasien bedah saraf. Sementara itu, therapeutic hypothermia memperpanjang penggunaan agen penghambat neuromuskuler (Neuromuscular Blocking Agent/ NMBA) serta memperpanjang pemulihan dari anestesi. Oleh karena itu, usaha mempertahankan kondisi normotermia lebih dipilih untuk semua kraniotomi elektif. ${ }^{10}$

\section{Teknik Pembedahan}

Pembedahan dengan teknik minimal invasif dapat dilakukan untuk kraniotomi dan bedah spinal. Kelebihan teknik ini yaitu meningkatkan persepsi diri pasien secara kosmetik karena sayatan kraniotomi yang kecil dan tersembunyi. Selain mengurangi nyeri sekunder pascaoperasi karena berkurangnya diseksi otot temporalis dan jaringan lunak, teknik ini juga menghindari transeksi dari saraf sensorik utama di daerah kepala. Pada bedah spinal, teknik bedah minimal invasif dapat meminimalisir estimasi perdarahan intraoperasi, trauma pada otot-otot punggung, dan risiko infeksi. Selain itu, teknik ini juga mempercepat mobilisasi pascaoperasi serta secara signifikan mengurangi penggunaan opioid pada manajemen nyeri pasca operasi. Namun, belum banyak randomized controlled trial (RCT) terkait teknik bedah minimal invasif pada bedah saraf sehingga penelitian lebih lanjut dibutuhkan., ${ }^{9} 10$ Teknik embolisasi praoperasi pada kasus tumor digunakan untuk mengurangi perdarahan, memperluas nekrosis tumor, dan berefek pada turunnya durasi rawat inap. ${ }^{19}$ Selain itu manajemen drainase cairan serebrospinal, dengan teknik lumbal pungsi atau drainase lumbal kontinuu, dapat mengurangi tekanan intrakranial yang berefek pada relaksasi otak dan berkurangnya edema serebri sehingga diseksi jaringan otak menjadi lebih mudah dan mengurangi cedera parenkim otak, serta mengurangi kebocoran cairan serebrospinal sehingga luaran menjadi lebih baik. ${ }^{20}$

\section{ERAS pada Perawatan Pascaoperasi}

\section{Analgesia}

Kraniotomi dapat menyebabkan nyeri moderat hingga berat pascaoperasi. Nyeri pasca operasi kraniotomi dapat muncul segera pasca operasi dan tetap dirasakan hingga beberapa bulan setelahnya. Oleh karena itu, pasien membutuhkan manajemen nyeri yang baik dan penggunaan analgesia pasca operasi. ${ }^{10}$ Gabapentin, pregabalin, dan tramadol kurang disarankan untuk pasien kraniotomi. Gabapentin terbuktiefektifmenguranginyeripasca operasidan konsumsi analgesia, namun dapat meningkatkan waktu ekstubasi dan skor sedasi pascaoperasi secara signifikan. Pregabalin menunjukkan adanya efek gangguan kognitif ringan pada pasien. Sementara tramadol menunjukkan peningkatan risiko PONV dan kejang. Analgesia lain, seperti obat antiinflamasi non steroid (NSAID) dan asetaminofen terbukti efektif mengurangi nyeri pascaoperasi. Selain itu, asetaminofen juga dapat 
menurunkan risiko terjadinya PONV. Namun, penggunaan NSAID golongan COX-1 inhibitor memerlukan pertimbangan lebih lanjut karena menyebabkan peningkatan risiko perdarahan. ${ }^{10}$

Post-operative Nausea and Vomiting (PONV) Insiden PONV mencapai $47 \%$ pasca kraniotomi. PONV dapat menyebabkan peningkatan tekanan intrakranial, risiko perdarahan, edema otak, dan aspirasi. Antagonis reseptor serotonin (misalnya, ondansetron) dan deksametason sangat direkomendasikan untuk mengatasi PONV. Skopolamin dan prometazin memiliki efek samping kurang sesuai sebagai obat antimual lini pertama untuk pasien pasca kraniotomi, seperti gangguan penglihatan, kebingungan, dan efek sedasi. ${ }^{10}$

\section{Drainase Urin}

Pelepasan kateter urin lebih awal terbukti menurunkan risiko infeksi serta meningkatkan mobilisasi pasca operasi. Kateter urin direkomendasikan untuk dilepas satu hari pasca operasi atau sedini mungkin. ${ }^{10}$

\section{Asupan Nutrisi}

Penggunaan opioid yang minimal dan daerah pembedahan yang jauh dari saluran gastrointestinal menyebabkan ileus pasca operasi jarang terjadi pada populasi bedah saraf. Pasien bedah saraf umumnya dimotivasi untuk memulai makan dan minum beberapa jam pascaoperasi. Asupan nutrisi dini pasca operasi menghasilkan proses pemulihan yang lebih cepat dengan hasil fungsional yang lebih baik. ${ }^{9,10}$

\section{Mobilisasi Dini}

Studi menunjukkan bahwa mobilisasi dini pada pasienpascabedahsarafdapatmencegahtrombosis vena, mencegah penurunan massa otot tubuh, menurunkan tingkat infeksi, dan mempersingkat lama perawatan di RS. Mobilisasi dini juga mempercepat kembalinya fungsi fisiologis tubuh pasien dan pasien dapat segera menjalani tahap perawatan selanjutnya seperti rehabilitasi. ${ }^{10,20}$

\section{Follow up Pasca Pemulangan}

Tindak lanjut/ follow up jangka pendek pasien bedah saraf disarankan untuk dilakukan pasea tindakan pembedahan. Tindak lanjut dapat dilakukan melalui wawancara telepon oleh perawat atau dokter maupun dengan pemeriksaan langsung di rumah sakit. Tindak lanjut disesuaikan dengan kebutuhan pasien. Data dari tindak lanjut melalui telepon akan melengkapi data tindak lanjut rutin ketika pasien datang ke rumah sakit.

\section{Penerapan ERAS pada Pasien Tumor Bedah Saraf}

Pasien kanker yang akan menjalani operasi dapat mengambil keuntungan dari pendekatan ERAS dengan pemulihan pascaoperasi yang lebih cepat dan dapat memulai rehabilitasi atau perawatan penunjang non-bedah lebih awal. Secara lebih spesifik, teknik pembedahan minimal invasif pada bedah spinal sangat direkomendasikan pada pasien kanker yang mengalami keterlibatan tulang belakang. .6 Beberapa penelitian yang menggunakan konsep ERAS pada pasien tumor bedah saraf yang menjalani prosedur tulang belakang menunjukkan kelayakan dan efektivitas ERAS pada pengendalian nyeri perioperasi dengan didapatkannya skor nyeri yang lebih kecil dan konsumsi opioid yang lebih sedikit dibandingkan pasien yang telah menjalani operasi sebelum penerapan ERAS. Sementara itu, intervensi ERAS untuk kraniotomi tumor otak juga direkomendasikan karena dapat mempercepat pemulihan fungsional, mengurangi lama perawatan, dan memungkinkan pasien untuk memulai kemoterapi dan/atau radiasi adjuvan dengan lebih cepat. Semua hal tersebut merupakan prediktor survival jangka panjang pada pasien atmor 6

\section{Penerapan ERAS pada Pasien Lansia}

Pasien yang lebih tua dan lemah berisiko lebih tinggi mengalami komplikasi setelah operasi abdomen mayor (British Geriatrics Society), maka dari itu protokol ERAS memiliki dampak positif pada hasil operasi untuk kelompok pasien ini. Protokol ERAS meminimalkan reaksi stress pada berbagai sistem organ yang mungkin sudah terganggu pada pasien lansia. Hal serupa juga dapat diaplikasikan pada pasien lansia yang akan menjani bedah saraf. Oleh karena jumlah 
literatur yang minimal, terdapat informasi yang terbatas terkait jenis pembedahan yang telah dipelajari dan protokol serta rekomendasi yang ada mengenai penerapan ERAS pada pasien lansia. sehingga dibutuhkan penelitian lebih lanjut terkait penerapan ERAS pada kelompok pasien lansia di bidang bedah saraf.

\section{Simpulan}

Penerapan ERAS dalam bidang bedah saraf dapat meminimalkan stres perioperasi dan menghasilkan keluaran yang lebih baik. Rekomendasi yang sudah diketahui sampai saat ini menunjukkan ERAS memberikan hasil yang baik, dapat diterapkan, dan memberikan keuntungan bagi pasien yang menjalani bedah saraf. Walau demikian, protokol ERAS dalam bedah saraf masih sangat terbatas dan memerlukan penelitian lebih lanjut mengikuti berbagai jenis tindakan/ operasi dan keadaan pasien yang berbeda-beda..

\section{Daftar Pustaka}

1. Kehlet H. Multimodal approach to control postoperative pathophysiology and rehabilitation. Br J Anaesth. 1997 May 1;78(5):606-17.

2. Ljungqvist $\mathrm{O}$, Hubner M. Enhanced recovery after surgery-ERAS - principles, practice and feasibility in the elderly. Aging Clin Exp Res. 2018 Mar 1;30(무):249-52.

3. Małczak P, Pisarska M, Piotr M, Wysocki M, Budzyński A, Pędziwiatr M. Enhanced recovery after bariatric surgery: systematic review and meta-analysis. Obes Surg. 2017 Jan $\underline{1} ; 27(\underline{1}): 226-35$.

4. Taurchini M, Del Naja C, Tancredi A. Enhanced recovery after surgery: a patient centered process. J Vis Surg. 2018; 4: 40.

5. Senturk JC, Kristo G, Gold J, Bleday R, Whang E. The development of enhanced recovery after surgery across surgical specialties. J Laparoendosc Adv Surg Tech. 2017 Aug 10;27(9):863-70.
6. Hagan KB, Bhavsar S, Raza SM, Arnold B, Arunkumar R, Dang A, et al. Enhanced recovery after surgery for oncological craniotomies. J Clin Neurosci. 2016 Feb 1; $24: 10-\underline{6}$.

7. Gjessing PF, Constantin-Teodosiu D, Hagve M, Lobo DN, Revhaug A, Irtun Ø. Preoperative carbohydrate supplementation attenuates post-surgery insulin resistance via reduced inflammatory inhibition of the insulin-mediated restraint on muscle pyruvate dehydrogenase kinase 4 expression. Clin Nutr. 2015 Dec 1; 34(ㅁ):11777-83.

8. Yu L-Y, Pei Y. Insulin neuroprotection and the mechanisms. Chin Med J (Engl). 2015 Apr 5; 128(7):976-81.

9. Lau D, Ziewacz JE, Siddiqi HK, Pelly A, Sullivan SE, El-Sayed AM. Cigarette smoking: a risk factor for postoperative morbidity and 1-year mortality following craniotomy for tumor resection: Clinical article. J Neurosurg. 2012 Jun 1;116(6):120414.

10. Oppedal K, Møller AM, Pedersen B, Tønnesen H. Preoperative alcohol cessation prior to elective surgery. Cochrane Database Syst Rev. 2012 Jul 11;(7):CD008343.

11. Hamilton MG, Yee WH, Hull RD, Ghali WA. Venous thromboembolism prophylaxis in patients undergoing cranial neurosurgery: a systematic review and meta-analysis. Neurosurgery. 2011 Mar 1;68(3):571-81.

12. Geze S, Yilmaz AA, Tuzuner F. The effect of scalp block and local infiltration on the haemodynamic and stress response to skull-pin placement for craniotomy. Eur $\mathrm{J}$ Anaesthesiol EJA. 2009 Apr;26(4):298-303.

13. Zhu Y, Yin $\mathrm{H}$, Zhang $\mathrm{R}$, Ye $\mathrm{X}$, Wei J. Therapeutic hypothermia versus normothermia in adult patients with traumatic brain injury: a meta-analysis. SpringerPlus. 2016 Jun 21;5(1):801. 
14. Shah A, Choudhri O, Jung H, Li G. Preoperative endovascular embolization of meningiomas: update on therapeutic options. Neurosurg Foucus. 2015;38(3):E7

15. Liu B, wang Y, Zheng T, Liu S, Lv W, Lu D, et al. Effect of intraoperative lumbar drainage on gross total resection and cerebrospinal fluid leak rates in endoscopic transsphenoidal surgery of pituitary macroadenomas. World Neurosurg. 2020;135:e629-e639

16. Türe H, Sayin M, Karlikaya G, Bingol CA, Aykac B, Türe U. The analgesic effect of gabapentin as a prophylactic anticonvulsant drug on postcraniotomy pain: a prospective randomized study. Anesth Analg. 2009 Nov;109()):1625-1631.

17. Salinsky M, Storzbach D, Munoz S. Cognitive effects of pregabalin in healthy volunteers: a double-blind, placebo-controlled trial.
Neurology. 2010 Mar 2;74(9):755-61.

18. Simon E, Bank J, Gal J, Siro P, Novak L, Fulesdi B, et al. Administration of preemptive analgesia by diclofenac to prevent acute postcraniotomy headache. Ideggyogyaszati Szle. 2012 Sep 1;65(9-10):302-․․

19. Latz B, Mordhorst C, Kerz T, Schmidt A, Schneider A, Wisser G, et al. Postoperative nausea and vomiting in patients after craniotomy: incidence and risk factors: clinical article. J Neurosurg. 2011 Feb $\underline{1 ; 114(2)}: 491-\underline{6}$.

20. Elsarrag M, Soldozy S, Patel P, Norat P, Sokolowski JD, Park MS, et al. Enhanced recovery after spine surgery: a systematic review. Neurosurg Focus. 2019 Apr $\underline{1} ; 46(\underline{4}): \mathrm{E} \underline{3}$. 